\title{
LA SUCESIÓN AL TRONO DE CASTILLA: 1275-1304
}

\author{
Manuel GONZÁLEZ JIMÉNEZ \\ Universidad de Sevilla
}

1. En noviembre de 1386, en pleno avance hacia la meseta de las tropas inglesas y gasconas del príncipe inglés Juan de Gante, desembarcadas meses antes en Galicia, Juan I de Castilla reunió Cortes en Segovia. Debía de hacer frente a una nueva amenaza. Ya no se trataba del enemigo portugués que le había infligído el año anterior la tremenda derrota de Aljubarrota, donde se habían hundido las esperanzas de ser reconocido como rey de Portugal. En esta ocasión venían a su propia casa a disputarle el derecho a ser rey de Castilla.

El origen de este nuevo conflicto es bien conocido: la muerte de Pedro I en Montiel en 1369 había roto la línea legítima de sucesión al trono castellano, para dar paso a la rama bastarda de Alfonso XI, en la persona del conde Enrique de Trastámara. Juan de Gante, que había casado en 1372 con Constanza, hija mayor y heredera de Pedro, habida de su unión - legítima al parecer- con María de Padilla, reclamaba desde entonces los derechos al trono castellano. La derrota de Juan I en Portugal se presentaba como la gran oportunidad para hacer efectivo su sueñot.

Este nuevo problema, añadido al desastre militar del año anterior, llevó a Juan I a plantearse el problema de su propia legitimidad como rey. No es que dudase de ella. Pero debía fundarla sobre bases más sólidas que la brutalidad de un golpe de estado, por más que estuviese justificado por la crueldad del rey asesinado o, como afirmaba la propaganda trastamarista, por el origen espurio de «aquel mal tirano que se llamaba rey», hijo, no de Alfonso XI, sino de un judío llamado Pero Gil. De esta forma, en un

1 La obra fundamental sobre el reinado de Juan I es el libro de Luis SUÁREZ FERNÁNDEZ, Historia del reinado de Juan I de Castilla (Madrid, 1977), refundida en Juan I. 1379-1390 (Palencia, Diputación Provincial, 1994). Sobre Juan de Gante, Anthony GOODMAN, John of Gaunt. The Exercise of Princely Power in Fourteenth-Century Europe (Harlow, Logman, 1992). Ver especialmente, 111-143. 
discurso sorprendente ante los asistentes a las Cortes de Segovia, Juan I declaró, de un plumazo, que todos los reyes anteriores a Enrique II, su padre, debían ser considerados como ilegítimos ya que descendían de Sancho IV que con codiçia desordenada e mala de rregnar, fizo en tal manera que deseredó asu padre en vida, e despues dela muerte del dicho su padre rretuuo al rregno e al senorio por fuerza alos dichos sus sobrinos, los llamados infantes de la Cerda, nietos de Alfonso X el Sabio².

2. La historia de este conflicto dinástico, desde sus orígenes en 1275 hasta la Sentencia Arbitral de Torrellas, va a ser el tema de esta ponencia. Treinta años de historia, durante los cuales volverá a plantearse una nueva crisis sucesoria, la de la minoría de Fernando IV, ambas enormemente interesantes.

El prof. Sánchez-Arcilla ha afirmado que hasta tiempos de Alfonso XI Castilla careció de una norma precisa que regulase «el orden de sucesión a la corona» ¿ ¿Carecía o no había sido promulgada? Ya lo veremos. De momento recordemos cuál era a mediados del siglo XIII la norma tradicional: primogenitura por línea masculina y, en defecto del primogénito, el mayor de los hijos supervivientes. A falta de hijos varones, podian acceder al trono las mujeres. Estos fueron los principios que rigieron la sucesión al trono durante los siglos XI, XII y XIII, desde la muerte sin sucesión de Sancho II (1072) hasta el accidente que puso fin a la corta vida de Enrique I (1217). Y así hubiera seguido siendo de no haber sido por la recepción en Castilla del ius commune, de la mano, principalmente, de los códigos mandados componer por Alfonso $\mathrm{X}$ el Sabio.

Por lo que hace al asunto que nos ocupa, las Partidas son el texto fundamental, $y$, en ellas, el famoso pasaje de la Partida II, título xv, ley ii que dice:

«por ende establesçieron que sy fijo varon y non oviese, la fija mayor heredase el rregno, e aun mandaron que sy el fijo mayor moriese ante que heredase, sy dexase fijo o fija que oviese de muger legítima, que aquel o aquella lo oviese, e non otro ninguno; pero sy todos estos fallesçiesen deve heredar el rregno el mas propinco pariente que y oviere seyendo omne para ello e non aviendo fecho cosa por que lo deviese perder" ${ }^{4}$.

Muy lejos estaba el Rey Sabio de pensar que esta intrusión en el derecho público de un principio de derecho privado romano (ius representationis) iba a provocar no sólo la división del reino y en el seno su propia familia, sino una guerra civil que sólo interrumpiría el fallecimiento del rey Sabio en abril de 1284.

Dejando aparte, de momento, lo que hubo de personal en el conflicto y ciñéndonos a los aspectos jurídicos de la cuestión, debemos plantearnos ante todo el problema

2 Cortes de los antiguos reinos de León y Castilla [CLC], II (Madrid, Real Academia de la Historia, 1863), 352-354.

3 José SÁNCHEZ-ARCILLA BERNAL, Alfonso XI. 1312-1350 (Palencia, 1996), 32.

4 Partida Segunda de Alfonso $X$ el Sabio. Manuscrito 12794 de la B.N. Edición: Aurora Juárez Blanquer y Antonio Rubio Flores, con estudios de C. Torres Delgado, J. Montoya Martínez, A. Juárez Blanquer y A. Rubio Flores (Granada, 1991), 135. 
de la vigencia o no de las Partidas al producirse en el otoño de 1275 el fallecimiento del primogénito de Alfonso $X$, el infante don Fernando de la Cerda.

Tradicionalmente se viene afirmando que las Partidas no fueron promulgadas en vida de su autor. Sólo alcanzarían vigencia legal en tiempos de su bisnieto Alfonso $\mathrm{X}$ $\mathrm{XI}$ quien, en el Ordenamiento de Alcalá de 1348 reconoció las Partidas «como derecho oficial del reino castellano-leonés» 5 . Pero, sin discutir la historicidad de esta sanción alfonsina perfectamente documentada, podríamos preguntarnos si Alfonso $X$ no dio valor de ley, siquiera fuese de forma tácita, a un código en el que tantas ilusiones había depositado. ¿Qué sentido hubiera tenido efectuar tan magna recopilación en la que se invirtió tanto tiempo y dinero sino su efectiva puesta en práctica?

La respuesta no puede ser más que positiva: en vida de Alfonso $X$ las Partidas estuvieron plenamente vigentes, ya sea por su simple promulgación en un acto de la corte del rey, cosa de la que no tenemos constancia o, como quiere O'Callaghan, por el simple hecho de ser las Partidas una revisión ampliada del Espéculo, código que había sido promulgado en Palencia en 1255 y cuya revisión se reservó el rey en el caso de que fuese necesario. Si esto es así, concluye $O^{\prime}$ Callaghan, las Partidas «no requerían ser promulgadas por separado". Por tanto, «tuvieron fuerza de ley durante el reinado de Alfonso $X{ }^{6}$.

Esta tesis podría corroborarse con otros dos argumentos. En el testamento de Alfonso X, redactado en Sevilla, el 8 de noviembre de 1282, se incluye un párrafo que puede interpretarse en el sentido propuesto por O'Callaghan:

«E porque es costumbre e derecho natural e otrosy fuero e ley de Espanna que el fijo mayor deue heredar los reynos e el sennorío del padre, non faziendo cosas contra estos derechos sobredichos por que lo aya de perder, por ende, nos, seguiendo esta carrera, después de la muerte de don Fernando, nuestro fijo mayor, como quier que el fijo que él dexasse de su muger de bendiçión, si él vizquiera más que nos, por derecho deue heredar lo suyo, asy commo lo deuía de heredar el padre; mas pues que Dios quiso que saliese del medio que era linea derecha por do desçendía el derecho de nos a los sus fijos, nos catando derecho antiguo e la ley de razón, segund la ley de Espanna, otorgamos <estonçe> e concedimos a don Sancho, nuestro fijo mayor, que lo oviese en lugar de don Fernando, nuestro fijo mayor, porque era más llegado por linea derecha que los nuestros nietos, fijos de don Fernando" 7 .

Aquilino Iglesia ha llamado la atención sobre el hecho de que en el texto que acabamos de leer se hace referencia a dos derechos diferentes: el derecho en virtud del

5 J. SÁNCHEZ-ARCILLA, ob. cit., 282.

6 Joseph F. O'CALLAGHAN, El rey Sabio. El reinado de Alfonso X de Castilla. Trad. de M. González Jiménez (Sevilla, Universidad, 1996), 62.

7 M. GONZÁLEZ JIMÉNEZ (Ed.), Diplomatario Andaluz de Alfonso X (Sevilla, 1991), n. 518 , p. 549 . 
cual el hijo del infante debía heredar a su padre y el derecho antiguo al que Alfonso $X$ se acogió para alterar las previsiones sucesorias establecidas por él mismo en las Partidas ${ }^{8}$.

Pero existe otro argumento a favor de la tesis de la vigencia de las Partidas en tiempos de Alfonso $\mathrm{X} y$, por tanto, del pleno vigor de las disposiciones referentes a la sucesión. Hace muchos años, el prof. MacDonald, experto conocedor de los textos jurídicos alfonsíes y editor reciente del Espéculo, llamaba la atención sobre la existencia de algunos manuscritos de la II Partida en los se alteró el sentido de la ley ii del título xiii de la manera siguiente: donde se lee sy el fijo mayor moriese ante que heredase, sy dexase fijo o fija que oviese de muger legítima, que aquel o aquella lo oviese, e non otro ninguno se hizo una habilidosa alteración/interpolación quedando el texto como sigue:

«si el fijo mayor muriese ante que heredase, si dexase fijo legitimo varon, que lo ouiese, pero si fincare otro fijo varon del rey que aquel lo herede et non el nieton ${ }^{9}$.

¿Qué sentido tendría esta manipulación del texto de las Partidas si no hubiesen tenido vigencia de ley? Evidentemente, ninguno. Por su parte Craddock, estudiando la misma interpolación, realizada según MacDonald en 1276, advierte que también se alteró en el código la edad legal fijada para poder reinar, veinte años, y se rebajó a diecisiete, precisamente la misma que tenía entonces el infante don Sancho ${ }^{10}$. "De esta forma - comenta O'Callaghan-, si el rey fallecía de repente, no habría necesidad de regencia ya que Sancho tenía ya diecisiete años»"11.

Desde el punto de vista histórico la sucesión de Alfonso $X$ plantea, en general, menos problemas. Uno de ellos - habida cuenta la energía con la que Felipe III de Francia defendió los derechos de sus sobrinos los infantes de la Cerda- es el de la existencia o no de una cláusula en las capitulaciones matrimoniales entre don Fernando de la Cerda y doña Blanca de Francia que estableciese el cumplimiento de las previsiones sucesorias en el orden previsto por las Partidas. El cronista catalán Bernat Desclot señaló a este respecto lo siguiente: avia covinença... que, aprés la mort d'En Ferrando, deguessen ésser sos nobots reis [existía el acuerdo de que después de la muerte de don Fernando, fuesen reyes sus nietos] ${ }^{12}$. Y una versión de la Cuarta Crónica General, de mediados del siglo XV, recoge la misma noticia cuando comenta que

8 Aquilino IGLESIA FERREIRÓS, "La labor legislativa de Alfonso X el Sabio", en España y Europa. Un pasado jurídico común (Murcia, Instituto de Derecho Común, 1986), 586-587.

9 R.S. MACDONALD, "Alfonso the Learned and Succession: A Father's Dilemma», Speculum, vol. XL (1965), 651, nota 11.

10 Jerry R. CRADDOCK, «Dynasty in Dispute: Alfonso $X$ el Sabio and the Succession to the Throne of Castile and León in History and Legend», Viator, 17 (1986), 197-219.

11 J.F. O'CALLAGHAN, EI Rey Sabio, 284.

12 Crònica del rei en Pere [III]. Ed. F. Soldevila, Les quatre grans cròniques (Barcelona, 1983), $454 a-b$. 
"este infante don Ferrando, seyendo infante, casó con la fija del rey de Françia que dezían donna Blanca. E casó con esta postura: que sy oviese en ella fijos, que reynasen en Castilla después dél... E éstos demandaron después el reyno grand tiempos'13.

3. El desarrollo del pleito sucesorio que estas disposiciones provocaron es difícil de resumir en pocas palabras. Intentaré de todas formas ofrecer un relato inteligible de los acontecimientos ${ }^{14}$.

Como dijimos, el problema de la sucesión de Alfonso $X$ se planteó de forma inopinada y, además, en el momento y en las circunstancias menos oportunas. Desde fines de 1274, Alfonso X estaba ausente del reino, tratando en Belcaire con el papa la resolución del fecho del Imperio, en el que había gastado tantas ilusiones, energías y dinero. Fernando de la Cerda había quedado como regente del reino. Fue entonces cuando se produjo la invasión de los benimerines y la ruptura de la tregua que Granada había firmado con Castilla años antes. El infante, que andaba por Valladolid cuando se produjeron estos hechos, se dispuso a acudir a la Frontera, falleciendo de forma inopinada en Villa Real en julio, según unos, o en octubre de 1275, según otros. En ausencia del rey, el infante don Sancho se hizo cargo del gobierno del reino y tomó medidas muy acertadas para contener la amenaza de granadinos y benimerines.

A su regreso de Belcaire sin haber conseguido del papa más que una rotunda negativa a sus pretensiones imperiales, Alfonso $X$ debió afrontar, entre otros problemas, el de la sucesión. La legalidad vigente -las propias leyes que él mismo había elaborado- y hasta los compromisos diplomáticos adquiridos le obligaban a reconocer como sucesor a don Alfonso, primogénito del infante don Fernando de la Cerda. $Y$ un sector de la nobleza, encabezado por el poderoso don Juan Núñez de Lara, señor de Albarracín, exigía que el rey se pronunciase en este sentido. Pero, por otro lado, la mayoría de la nobleza, destacando entre todos don Lope Díaz de Haro, señor de Vizcaya, y la mayoría del reino pedian que se aplicase el derecho tradicional. De la misma opinión era el infante don Manuel, hermano menor de Alfonso $X$ y tío de Sancho, quien, a instancias del monarca, expresó su opinión al respecto con esta bella sentencia que recoge la Crónica de Alfonso $X$ :

«El árbol de los reyes non se pierde por postura nin se deshereda por y al que viene por natura. Et sy el mayor que viene del árbol fallesçe, deve fincar la rama de so él en somo».

Que era lo mismo que decir que ningún tratado o postura podía ir en perjuicio del que por ley natural tiene todos los derechos, y que, por tanto, en faltando el hijo mayor, debía sucederle quien le siguiese en edad.

13 J.R. CRADDOCK, "Cronología de las obras legislativas de Alfonso X el Sabio", Anuario de Historia del Derecho Español, Ll (1981), 403.

14 Sigo de forma resumida lo que expuse en mi libro Alfonso X. 1252-1484 (Palencia, Diputación Provincial, 1993), 123-155. 
Se discute cuál era la opinión de otros miembros de la familia real, especialmente de la reina doña Violante. Se mantuvo al lado del rey mientras se discutieron los derechos de unos y otros, como sucedió en la Cortes de Burgos de 1276 que parece que dieron la razón a don Sancho aunque sin reconocerle aún como el heredero oficial. Esto sucedió en las Cortes de Segovia de 1278.

Entre una y otra reunión de Cortes pasaron en Castilla muchas cosas, y algunas de especial gravedad. Muchos nobles, incluso partidarios destacados de don Sancho, hubieron de exiliarse a Francia, cuyo rey amenazaba con invadir Castilla al frente de un poderoso ejército. Pero lo más grave fue una oscura conjura encabezada por don Fadrique, hermano del rey, que concluyó con la prisión y ajusticiamiento del infante y de don Simón Ruiz de los Cameros. Se discuten los motivos que indujeron al rey para dictar una sentencia tan dura. Basándose en unos pasajes de las Cantigas de Santa María, Kinkade ha hablado de la homosexualidad de ambos personajes ${ }^{15}$. No creo que fuese ésta la causa. Me inclino más bien por pensar que don Fadrique trató, a la vista de lo confuso de la situación, de las dudas de Alfonso $X$ en reconocer oficialmente a Sancho como infante heredero y de la impopularidad creciente del monarca, que había dado ya suficientes muestras de incompetencia política, de dar un golpe de estado y proclamarse él mismo rey o, por lo menos, regente hasta tanto se resolviese el problema de la sucesión.

El reconocimiento de Sancho como hijo mayor heredero, en abril de 1278, trajo la tranquilidad al reino, si bien provocó la huida a Aragón de la reina, acompañada de su nuera y de sus nietos los infantes de la Cerda. O'Callaghan piensa que la huida de doña Violante se debió «más a la ruptura de su matrimonio que a su temor por la vida de los infantes de la Cerda ${ }^{16}$. Si esto es así, no se entiende muy bien por qué la acompañaron la viuda y los hijos de don Fernando de la Cerda. Pero, sea como fuere, el hecho es que a partir de este momento las relaciones entre el rey y su mujer quedaron prácticamente rotas, a pesar del regreso de ésta a Castilla un año y medio después de su partida, cargada de deudas y habiendo dejado en manos de Pedro III de Aragón a los infantes de la Cerda. El infante don Sancho, que satisfizo las deudas de su madre con el dinero que se recaudaba en Castilla para el ejército que sitiaba Algeciras, no fue ajeno del todo a estos hechos. Dadas sus buenas relaciones con el su tío rey aragonés, parece más que probable que la decisión de encerrar a los infantes en Játiva debió contar con la aprobación del infante. De esta forma, alejaba de Castilla a los posibles herederos del rey, al tiempo que ponía en manos de Pedro III una importante baza política que podía emplear en sus difíciles relaciones con Francia.

Por lo que hace a Alfonso X, desde las Cortes de Burgos de 1276, las relaciones con Felipe III de Francia eran especialmente tensas. En 1280 se acercó a Bayona para negociar una solución aceptable del pleito de los infantes de la Cerda. El rey

15 R.P KINKADE, «Alfonso X, Cantiga 235, and the Events of 1269-1278», Speculum 67-2 (1992), 313-318.

16 J.F. O'CALLAGHAN, El Rey Sabio, 293. 
castellano estaba dispuesto a entregar al mayor de sus nietos, Alfonso de la Cerda, el reino de Jaén en concepto de feudo. Felipe III rechazó una oferta tan poco generosa y manifestó exigiendo que, cuando menos, se diese a su sobrino el reino de Castilla o el de León. La propuesta - a todas luces inaceptable para Alfonso X- fue rechazada de plano, con lo que las negociaciones se dieron por rotas.

En octubre de 1281, durante las celebración de una reunión de Cortes en Sevilla, tuvo lugar un duro enfrentamiento entre Alfonso y Sancho, que se negaba en redondo a aceptar cualquier solución al problema que atentase contra la integridad territorial del reino. El infante - que contaba ya con el apoyo de las ciudades y de buena parte de la nobleza y del clero- abandonó la ciudad con el pretexto de negociar una tregua con los granadinos. En realidad, se disponía a ponerse al frente de una sublevación contra el rey. La guerra civil estaba a punto de estallar.

4. Todo conflicto civil plantea al historiador un problema: tratar de ver con claridad los hechos y emitir una opinión objetiva sobre los mismos. En el caso que nos ocupa el problema se complica por la absoluta parcialidad de las fuentes historiográficas conservadas que, en líneas generales, fueron redactadas por autores partidarios o simpatizantes de don Sancho. Desde luego, el autor de la última sección de la Crónica de Alfonso $X$ toma partido claramente por el infante. Lo mismo puede decirse del anónimo autor de unos anales del reinado de Alfonso $X^{17}$ y de don Pedro, conde de Barcelos que nos ha transmitido una copia casi literal de la sentencia de la suspensión de Alfonso X en sus funciones de rey, pronunciada en Valladolid en abril de 1282 por el infante don Manuel.

En efecto, para reforzar su posición, Sancho reunió en Valladolid una magna asamblea que, tras breve deliberación, acordó retirar a Alfonso $X$ todos sus poderes y prerrogativas, manteniéndole el título de rey. El texto de la sentencia decía como sigue:

"Por quanto el rey don Alfonso mato a don Fadrique su hermano a don Ximon Ruyz señor de los Cameros e otros muchos fidalgos sin derecho commo non deuia, pierda la justiçia.

E porque deseredo los fijosdalgo de Castilla e de Leon e los çibdadanos e los conçejos, non lo resçiban en las villas nin en las fortalezas e sea deseredado dellas.

E porque despecho la tierra e fizo malas monedas, non le den pechos nin seruiçios nin monedas foreras nin las martiniegas nin otros derechos ningunos de la tierra avnque los demande ${ }^{18}$. 
la tumba, a pesar de que poco antes de morir el rey su padre manifestase la intención de perdonarle. Pero nunca lo hizo, al menos formalmente, aunque otra cosa diga el cronista. De haber sido así, no tendrían sentido las palabras que según don Juan Manuel pronunció Sancho en su lecho de muerte:

«... bien creed que esta muerte que yo muero non es muerte de dolençia mas muerte que me dan míos pecados et sennaladamente por la maldicion que me dieron mio padre por los muchos mereçimientos que les yo mereci» ${ }^{19}$.

Este asunto de la maldición de Alfonso $X$-olvidado casi por la historiografía oficial del siglo XIV- resucitó, como hemos visto, de la mano de Juan I en el discurso regio pronunciado ante las Cortes de Segovia. En él no sólo dio por buenos los efectos jurídicos de la maldición alfonsina, sino que reclamó su propia legitimidad acudiendo a su vinculación genealógica con el rey Sabio a través de su madre doña Juana Manuel, nieta del segundo hijo del infante don Fernando, llamado también Fernando como su padre.

De todas formas, quedaba el problema de la ilegalidad de Enrique II, que había sucedido por métodos violentos a su hermanastro Pedro I. Por mucho que la propaganda trastamarista se empeñase en proclamar la ilegitimidad de Pedro l e, incluso, como afirmara Juan I en 1386, en suponer que la bastardía de origen quedaba subsanada por el casamiento con doña Juana Manuel y por haber sido rresçibido e tomado por Rey eneste rregno, la sombra de duda sobre la legitimidad de la nueva dinastía no había desaparecido. Tal vez por ello comenzó a difundirse una supuesta profecía de la que se hicieron eco algunos cronistas y escritores de los siglos XIV y XV.

La profecía en cuestión está relacionada con la supuesta condena que contra Alfonso $X$ pronunció el mismo Dios por haber dicho en público que si hubiera estado al lado de Dios Padre cuando éste hizo el mundo muchas menguas $<q u e>y<s e>$ fizieron que non se fizieran. Por esto Dios le anunció que sus descendientes directos perderian el trono y que ello sucedería transcurridas cuatro generaciones a partir de su hijo Sancho ${ }^{20}$.

5. Pero todo esto, con ser interesante, es pura patraña, y la discusión simplemente jurídica contenía de por sí suficientes elementos de controversia como para necesitar de argumentos proféticos que la alentasen. Los hechos, a la altura de 1282, eran éstos: Alfonso $\mathrm{X}$, a la vista de la sublevación y traición de su hijo, deroga su nombramiento como heredero - hecho, no lo olvidemos, de acuerdo con el derecho antiguo o tradicional-y retoma su primera intención de aplicar lo dispuesto en las Partidas. Es decir, declara herederos del sennorío mayor de su reino a sus nietos

19 DON JUAN MANUEL, Libro de las armas, en A. GIMÉNEZ SOLER, Don Juan Manuel. Biografía y estudio crítico (Zaragoza, 1932), 689 [53].

20 Cf. M. GONZÁLEZ JIMÉNEZ, «Unos anales del reinado de Alfonso X», 482-486. 
"fijos de don Fernando, nuestro fijo, que fue primero heredero, de guisa que el mayor herede este nuestro sennorío e al otro le faga bien commo conviene, segund el fuero de Espanna manda fazer a los fijos que non han de aver el sennorío mayors ${ }^{21}$.

En el supuesto de que los infantes de la Cerda falleciesen sin dejar herederos, Alfonso $X$ dispuso que heredase el reino el rey de Francia, porque viene derechamente de línea derecha onde nos venimos del emperador de Espanna [Alfonso VII], e es bisnieto del rey don Alfonso de Castilla [Alfonso VIII], bien como nos, ca es nieto de su fija [la infanta doña Blanca, casada con Luis VIII de Francia] $]^{22}$.

Podría argumentarse que esta solución, aparentemente disparatada, es reflejo de una situación familiar que, por doloroso que fuese, Alfonso $X$ se vio obligado a reconocer: que en el otoño de 1282 toda su familia -la reina doña Violante, sus hijos los infantes don Juan, don Pedro y don Jaime, y hasta su hermano el infante don Manuel- estaban del lado del hasta entonces infante heredero don Sancho. En estas circunstancias, y descartado D. Dinís de Portugal, nieto del rey castellano, en razón del origen bastardo de su madre, sólo restaba el rey de Francia.

Ahora bien, lo interesante y hasta cierto punto extraño es que esta previsión sucesoria se mantuviese en la última voluntad o codicilo de Alfonso $X$, redactado el 10 de enero de 1284, cuando ya había vuelto a su obediencia el infante don Juan a quien el rey entregó, en pago de su fidelidad, los reinos de Sevilla y Badajoz. En buena lógica, Alfonso $X$ debería haber dispuesto que los derechos de los infantes de la Cerda pasasen de nuevo a la rama principal del linaje, representada por don Juan, y no a la rama de la casa de Francia, por muy emparentada que estuviese con la de Castilla. De haber sido así, el rey Sabio no hubiera tenido que volver a justificar su decisión argumentando que ninguno non puede dezir con derecho que de nuestro linage sacamos nuestro sennorío nin lo damos a estrannos ${ }^{23}$. $\mathrm{O}$, tal vez, este gesto de aparente inoportunidad política era algo más que un gesto para aplacar las reclamaciones de Francia; era, sin que así fuese formalmente reconocido, el reconocimiento de que la herencia de Alfonso VIII debería haber pasado en su condición de «hija mayor», no a doña Berenguela, madre de Fernando III, sino a su hermana doña Blanca, madre de Luis IX de Francia.

6. La muerte de Alfonso $X$ el 4 de abril de 1284 puso fin a la crisis sucesoria, al menos dentro del reino. El infante don Juan y todos los ricos hombres castellanos que se habían mantenido fieles al rey difunto - y en 1284 eran ya muchos- reconocieron como rey a don Sancho. Antes de que este reconocimiento se produjese, el nuevo monarca - nećesitado de apoyos sobre los que asentar su propia legitimidad- se había hecho coronar rey en Toledo en una ceremonia que tuvo lugar en la catedral y

21 M. GONZÁLEZ JIMÉNEZ (Ed.), Diplomatario Andaluz de Alfonso X, n. 518, p. 553.

22 Id., ibid., p. 554.

23 Diplomatario, n. 520 , p. 561. 
en la que actuaron de oficiantes los obispos de Burgos, Cuenca, Coria y Badajoz. Se trató de un gesto bastante inusual dentro de los ritos sucesorios castellanos. Alfonso $X$ no fue coronado cuando accedió al trono el 1ํ de junio de 1252. Fue, simplemente, alzado o aclamado por el pueblo24. Sancho IV - por razones obvias, tanto de cara al interior como al exterior del reino- no podía contentarse con una simple proclamación, como la que tuvo lugar en Avila, donde se enteró de la muerte de su padre. Debía efectuar -en el mejor de los ámbitos posibles: Toledo, la antigua ciudad donde se coronaban los reyes visigodos-y por la autoridad de cuatro obispos (dos por cada uno de los arzobispados que le eran fieles) un acto público que le presentase ante el reino como el verdadero depositario de la corona real de su padre, esa misma corona a la que Alfonso $X$ se había referido en su codicilo y que debía corresponder a aquél que con derecho e por nos heredare el nuestro sennorio mayor de Castella e de León ${ }^{25}$. Como ha señalado Linehan, «la coronación de Sancho IV fue un acto público tendente a mitigar los efectos de la sentencia de maldición de Alfonso $X$, y venía a proclamar que el nuevo rey había adquirido su reino con derecho. Fue calculada para legitimar su sucesión»26.

Pero los gestos - y los efectos propagandísticos de los mismos- no concluyeron aquí. Como ha escrito Linehan, «la ceremonia de Toledo no fue una mera coronación. Fue también una ceremonia eclesiástica de coronación, efectuada por cuatro obispos, la primera desde 1135. Además, la reina fue también coronada, probablemente por el propio Sancho ${ }^{27}$. Evidentemente, estos gestos y ceremonias no resolvieron el problema. Pero sirvieron sin duda para tranquilizar a la opinión pública del reino acerca de la legitimidad de origen del nuevo monarca.

7. La muerte prematura de Sancho IV en 1295, dejando como heredero a Fernando IV, menor de edad, destapó de nuevo la cuestión sucesoria. Ésta había quedado resuelta, en lo que a Francia se refiere, en el tratado de Bayona de 1290, en el que, además de ratificarse lo acordado en Lyon en 1288 respecto a las compensaciones económicas en favor de doña Blanca, viuda de don Fernando de la Cerda, Felipe IV el Hermoso renunció a sus posibles derechos al trono castellano, desentendiéndose "Completamente de la causa de los infantes de la Cerda" ${ }^{28}$. A partir de este momento, el valedor de los infantes sería el rey de Aragón, en cuyo reino estaban acogidos desde 1278. Había llegado el momento previsto por Pedro III en que los infantes iban a con-

24 Jofré de Loaysa, testigo presencial del acto, afirma que, tras el entierro de Fernando leuantaron a don Alfonso. Ver el texto en M. GONZÁLEZ JIMÉNEZ, "Andalucía en tiempos de Alfonso X. Estudio histórico", en Diplomatario, xxix.

25 Diplomatario, p. 559.

26 Peter LINEHAN, History and Historians of Medieval Spain (Oxford, Clarendon Press, 1993), $446-447$.

27 Ibid., 447.

28 J.M. NIETO SORIA, Sancho IV, 1282-1295 (Palencia, 1994), 104. Publica el texto G. DAUMET, Mémoire sur les relations de la France et la Castile de 1255 à 1320 (Paris, 1914), 200. 
vertirse en pieza de canje en el complicado tablero de la política peninsular y mediterránea de fines del siglo XIII.

En efecto, apenas muerto Sancho IV, el rey aragonés - que hasta entonces había mantenido unas excelentes relaciones con el rey castellano- denunció su acuerdo matrimonial con la infanta Isabel y la devolvió a su madre la regente doña María de Molina. Al mismo tiempo, reconoció como rey de Castilla y León a Alfonso de la Cerda y fraguó una compleja alianza anticastellana en la que entraron, además del infante don Juan, dispuesto siempre a crear problemas, Francia, Portugal y Granada. Fue entonces cuando se planteó la ilegitimidad de Fernando IV, hijo de la unión incestuosa y bígama entre Sancho IV y María de Molina ${ }^{29}$.

No es éste el momento de analizar con detalle el conflicto sobre la sucesión al trono de castellano y que dio lugar a un duro enfrentamiento entre Aragón y Castilla en el curso del cual se produjo la ocupación aragonesa del reino de Murcia y que se prolongaría hasta la Sentencia Arbitral de Torrellas de 1304. Baste recordar que se acordó el reparto del reino entre Alfonso de la Cerda, que recibiría los reinos de Castilla, Toledo, Córdoba y Jaén, el infante don Juan, que sería rey de León, Galicia y Sevilla, y Jaime II de Aragón, a quien Alfonso de la Cerda confirmó la donación del reino de Murcia hecha años antes a su hermano Alfonso III $^{30}$.

Como resultado de todo ello, en la primavera de 1296 se produjo la invasión de Castilla por un ejército aragonés. Mientras el infante don Pedro, hermano de Jaime II, penetraba hasta León, donde fue proclamado rey el infante don Juan, y Alfonso de la Cerda era igualmente proclamado rey de Castilla en Sahagún, Jaime Il procedía a la ocupación del reino de Murcia. La reina regente logró conjurar el peligro, y el ejército invasor, tras fracasar en su intento de apoderarse de la villa de Mayorga de Campos, se retiró a Aragón. No sucedió lo mismo en el sector murciano, que fue totalmente conquistado y retenido por Jaime II hasta 1304.

La resolución de la larga crisis tuvo lugar en la aldea de Torrellas, situada entre Tarazona y Agreda. A las vistas asistieron los reyes de Aragón y Castilla, además de D. Dinis de Portugal, que había sido designado previamente como árbitro del conflicto. Se trataba, por supuesto, de acabar con el enfrentamiento entre Fernando IV y Jaime II. Pero cada uno llevaba a las vistas su propia reclamación. En efecto, lo que de veras importaba a Jaime II era la delineación de una nueva frontera entre los reinos de Valencia y Murcia, adelantándola hasta la línea del río Segura e incorporando a sus reinos, entre otras, las tierras de Alicante, Elda, Novelda, Elche y Orihuela. El objetivo de Fernando IV era conseguir, al precio que fuese, la renuncia del de la Cerda a sus derechos al trono castellano. El acuerdo tuvo, por tanto, dos sacrificados: Alfonso de

29 María de Molina era prima hermana de Alfonso X y, por tanto, tía de Sancho IV. La ruptura de su compromiso matrimonial de éste con Guillerma de Moncada, hija del vizconde Guillermo VII de Bearn, nunca fue reconocida por la Iglesia. No obstante, Fernando IV fue legitimado por Bonifacio VIII en 1301. Cf. P. LINEHAN, ob. cit., 447 y nota 113.

30 La donación fue hecha en Calatayud el 26 de junio de 1289. Publicó el documento A. GIMÉNEZ SOLER, ob. cit., 221-223. Ha vuelto a editarlo J.M. del ESTAL, EI Reino de Murcia bajo Aragón: 12961305. Corpus Documental, I/1 (Alicante, 1985), 107-109. 
la Cerda, que debió contentarse con un importante, aunque disperso, señorío en Castilla, y el reino de Murcia, al que se le amputó el sector más rico y poblado ${ }^{31}$.

A partir de 1304, Alfonso de la Cerda dejó de emplear las armas y sello de Castilla y se integró en los cuadros de la alta nobleza castellana. Mantendría, con todo, y durante mucho tiempo, el resquemor de la derrota. En 1331, rondando ya los sesenta años, en el curso de una emotiva entrevista que tuvo lugar en su señorío de Burguillos, renunció de nuevo a sus derechos al trono castellano en manos de su sobrino Alfonso $\mathrm{Xl}^{32}$. Se cerraba así un largo contencioso que había durado más de cincuenta años. Las Partidas debieron ceder, en este punto concreto, ante el derecho tradicional no escrito que primaba la sucesión dentro de los propios hijos del monarca reinante, prefiriendo al varón sobre la mujer. Sólo tardíamente (1810, constitución de 1812 y Pragmática Sanción de 1830) volvería a estar en pleno vigor la ley $2^{\text {a }}$ del título 15 de la II Partida ${ }^{33}$. Pero este asunto, me temo, desborda con mucho el ámbito cronológico que ahora nos interesa.

31 Ver sobre esta asunto C. GONZÁLEZ MíNGUEZ, Fernando IV de Castilla (1295-1312). La guerra civil y el predominio de la nobleza (Vitoria, 1976). Del mismo autor, Fernando IV, 1295-1312 (Palencia, 1995).

32 Cf. J. SÁNCHEZ-ARCILLA, ob. cit., 163.

33 Ver los textos en A. GARCÍA GALLO, Manual de Historia del Derecho Español. II: Antología de Fuentes del Antiguo Derecho (Madrid, 1967), 1232-1235. 